\title{
The Impact of E - Accounting in Modern Businesses
}

\author{
Susan Peter Teru $P h D$ \\ Department of Accountancy \\ Taraba State University, Jalingo, Nigeria \\ E-mail: susan4dpt@gmail.com Tel: +234803653273I \\ Innocent Felix Idoko $P h D$ \\ Department of Business Administration \\ Taraba State University, Jalingo, Nigeria \\ E-mail: drifidoko@gmail.com \\ Lukman Bello \\ Department of Accountancy \\ Taraba State University, Jalingo, Nigeria
}

\begin{abstract}
There has been constant growth and development in information technology which had brought the digital revolution in our daily economic, social and cultural fields. This technological development changed the methods and ways of carrying out tasks within the scope of accounting transactions and activities through the use of electronic media. One of the digital applications produced on this issue is E- accounting. E-accounting is a new development in the field of accounting adopted at the international level. E-accounting stands for electronic accounting with the characteristics of high speed, accuracy and with an immediate result. Accordingly, source documents and accounting records exist in a digital form instead of on paper in an electronic accounting system. It helps businesses keep their financial data and accounting software in a safe, secure environment allowing real-time access to authorized users irrespective of their location or computing platforms. This paper sheds light on the impact of e-accounting in the modern business, the concept of E- accounting, benefits, and problems of e- accounting. The main source of data used for this paper is the secondary data from the review of related literature basically to create a theoretical background for the study. It was found from the studies that many organizations fail in the business, not because of poor quality of material, not the availability of trained staff, management problems, but the main reason is the accounting practices adopted by the businesses. Therefore, there is a need for businesses to adopt e -accounting practices as a replacement for traditional practices.
\end{abstract}

Keywords: Accounting, E- Accounting, Information, System, Technology.

\section{Introduction}

E-accounting is a newly emerging concept in the field of accounting. In E-accounting, source documents and accounting records exist in digital form instead of on a paper. This concept is accepted at an international level. It saves a lot of time and energy and saves paper and finally reduces the cost in any type of organization. On a daily basis, there is advancement in technology and new software is coming up for the recording of accounting transactions. Accordingly, accounting is one of the important functions of every organization; it is also called the mirror image of the business. The traditional accounting is a very time-consuming process of accounting compared to modern accounting practices. E-accounting involves education through various computerbased/internet-based accounting tools such as digital tools kits, web links, international web-based materials, various internet resources, institute and company databases which are internet based, internet-based accounting software and electronic financial spreadsheet tools to provide effective and efficient decision making. This study is intended to look at the topic impact of Eaccounting practices adopted by modern businesses. It was found from studies that many organizations are failing in business, not because of unavailability of high technology or trained staff, poor quality of material or management problems; but because 
of the accounting practices adopted by the businesses. Therefore, there is a need for businesses to adopt E-accounting as a replacement for traditional practices for efficient performance.

\section{Objectives of the Study}

The main objective of the study is to look at the conceptual background and the common features and benefit of e-accounting. More specifically, the study seeks to achieve the following objectives:

- To study the conceptual background of the term E - accounting.

- To study the features and impact of E - accounting.

- To study and examine the benefits and problems of E - accounting.

\section{Review of Related Literature}

Information technologies influence the business world and our social life today. In the aspect of accounting, accounting software is being used efficiently worldwide. There are many accounting software in the market for a unified accounting system. Along with unified accounting, accounting applications have increased rapidly and companies keep their records through such applications. Hence, record and management of transaction are now easier (Guney, 20I4).

Information Technology (IT) has significantly advanced during the past years, and the number of organizations that rely on a computer in the electronic operation of their statements also increased. Nowadays, most of the companies use the IT managing their data and delivering the same to their users, especially the e-accounting systems (Ghasemi et-al, 20II). Eaccounting refers to electronic accounting, a term used to describe an accounting system that relies on computer technology for capturing and processing financial data in organizations (Laudon \& Laudon 20II). Thus, accounting systems are used for recording, analyzing, monitoring and evaluating the financial condition of companies. According to Damodaran (2007), the financial condition refers to an assessment of the viability, stability, and profitability of a business. It is performed by preparing reports using ratios such as return on equity (ROE), return on asset (ROA) and return on investment (ROI) that make use of financial information taken from accounting systems in the financial statement to present a more comprehensive image of the firm's financial performance. These reports are usually presented to top management as one of their bases in making business decisions (Kieso et al., 2011).

Thus, the use of the computerized accounting systems led to the development of the financial performance as they provide statistical methods and testing tools which help in evaluating the performance and taking decisions (Toshniwal, 20I6). When organizations adopt e-accounting, they are able to generate immediate reports regarding the organization (Smith, I997). Accuracy and reliability of the report are important to take comprehensive decision by the manager.

According to (Hajera, 2016), one of the aspects of information technology effect on enterprises and institutions is quantitative and qualitative changes of information and accounting management systems. The leading developments are that of data and activity exchange, as well as the expansion of intranet and internet information networks. Consequently, we can claim that the role of electronic information networks in releasing financial and business information of the organization is unavoidable.

\section{Research Methodology}

We made use of secondary data in the analysis of the study. The data is collected from the review of related literature and several sources to the subject of study which are, research articles, scientific journals, books, websites, and some books on account ing and e-accounting in order to build the theoretical framework of e- accounting and fulfill its objectives.

\section{Role of E Accounting}

E-accounting or online accounting is the application of online and internet technologies to the business accounting function. It is a new development in the field of accounting and is adopted at the international level. E-accounting or online accounting is that in which all the transactions are recorded in an online server or database, just like a website or blog or web blog. Before opening or making use of the accounts, a login id and password is required. In E-Accounting, the accountant and employer both feel satisfied because it is cheap and without software defaults or failure. As the accounts are saved in an online server or database, there is no need of manual recording. By this means we can save a large amount of money on the manual book.

An electronic accounting system can be helpful in the effective process of accounting through the following features (Fitriati \& Mulyani, 20I5).

- Universal access.

- Large Scale Business Record.

- Multiple site access.

- Zero system administration for end-users. 
- Frugality because of service offering to a large number of customers.

- A single/ multiple, shared database (s).

- Enhancements and fixes continuously developed and installed by the service provider.

- Fast Record with Advanced Technology.

Online accounting through a web application is typically based on a simple monthly charge and zero-administration approach to help businesses concentrate on core activities and avoid the hidden costs associated with traditional accounting software such as installation, upgrades, exchanging data files, backup and disaster recovery.

\section{Benefit of E-Accounting}

Accurate financial and accounting information is very important for organizations to maintain a position over the competitors in the market. In a fast-paced world, the clients need to have access to their financial data at any point in time to know their financial positions. This is possible through e-accounting. E-accounting helps businesses keep their financial data in a safe, secure environment, allowing real-time access to authorized users, irrespective of their location or computing platform.

This is possible due to an Application Software that allows access to users of financial information with different levels of permission and password. In this regard, below are the main benefits and problems of e-accounting as given by Kumar and Preety (2012):

- It saves time and money.

- Gain greater control of finance by moving from paper records to computerized accounting software.

- Send sales invoice and other documents directly to another business accounts for the recipient to approve without having to reenter the information

- E-accounting may improve the effectiveness of accounting and reporting task, budgeting, controlling and auditing which may reflect on the organization effectiveness as well.

- Organization's entire accounting project can be easily outsourced by the accounting system.

- It generates employment opportunities for software developers and accountants.

- No need for in-house bookkeepers' training and expertise.

- No communication difficulties between the accountant and business owner or

- Organization due to load/work pressure.

- Cost saving on office space (rent for additional offices)

- Transactions that affect the company's bank account can be sent automatically to the

- Online accounting application.

- They are portable. The company can access its documents from almost any computer with a broadband connection.

- If the company's computer crashes, its documents are still safe on the server.

- Accounting packages now allow a business to trade in multiple currencies with ease.

- Data can be kept confidential by taking advantages of security password system that most accounting programs provide.

\section{Problems of E- Accounting \\ 7.I Data Security}

All the data of the company resides on a remote server or computers whose back up can be checked regularly. The data can be erased or lost due to problem with computers. Also, the data can be stolen by other companies.

\subsection{Speed}

Most of the currently available online office suites require a high broadband Internet connection.

\subsection{A network connection (usually Internet access) is required to send and receive changes. That is, internet dependence makes it more difficult to work offline. \\ 7.4 Special training is required.}

\section{Conclusion}

Evolution in information technology (IT) has led to the development of new accounting systems, improved economic models and business dealings through the Internet. These advances in information and communication technology (ICT) have reduced the time of the transaction, and cost by aiding increased and improved transactions and communication for business dealings. E accounting is used by many organizations to improve and advance the efficiency of their business dealings by computerizing existing operations to improve the performance of their operation. It can be used by the organizations as a device for achieving a stronger, reliable, and more corporate culture to survive in this competitive environment. 
Due to technological advancement, preparation and arrangement of accounting records are carried out in an electronic environment. By means of this development, various information is generated by the accounting system within a short time to the information users. Synchronous and comparable presentation of financial statement has become easier. Therefore, this study found that the most significant impact of E-accounting is on the development of technology, which saves time and cost for the user. E-Accounting is a borderless entity permitting banking anytime and anywhere. It has brought opportunities for companies to perform accounting functions more effectively and efficiently. Adaption of e - accounting functions has made companies progress towards paperless offices and also reduced the cost of clerical works by providing sufficient space to store data and process information for management decisions in a friendly manner.

It was found from various studies that many organizations are getting failure in their business not because of unavailability of high technology, poor quality of material, unavailability of trained staff or management problems but because of the accounting practices adopted by the businesses. Thus, it is necessary for businesses to adopt E-accounting practices as a replacement for traditional practices.

\section{References}

Fitriati, A., \& Mulyani, S. (2015). Factors that affect accounting information system success and its implication on accounting information quality. Asian Journal of Information Technology, I4(5), I54-I6I.

Ghasemi M., Valid S., Aslani M., \& Elham B. (20II). The Impact of Information Technology (IT) on Modern Accounting systems. Procedia - Social and Behavioral Sciences, (28) II2-II6.

Guney A. (2014). Role of technology in accounting and e- accounting. Procedia- Social and Behavioural Sciences. I52, 852855.

Hajera, F. (2016). Impact of e-accounting in today's scenario. International Journal of Engineering and Management Research. 6(I) 260- 264 .

http://www.svtuition.org/2008/12/e-accounting.html

https://en.wikipedia.org/wiki/E-accounting

Kieso, E., Weygandt J., \& Terry D. (20II). Intermediate Accounting I4 ${ }^{\text {th }}$ Edition. New Jersey USA, John Wiley \& Sons, Inc.

Kumar, S. \& Preeti J. (2012): What and why e - Accounting? The Economic Changer I4(55). PP I23

Laudon, K.C., and Laudon, J.P. (20I I). Management Information Systems: Managing the Digital Firm (Upper Saddle River, NJ: Prentice Hall).

Smith S. (I997):: The smart ways to invest in computers. Journal of Accountancy 63(I) 65.

Toshniwal, R. (2016). E- Accounting: the necessity for modern businesses. $4^{\text {th }}$ International Conference on Science, Technology, and Management. ISBN: 978-8I-932074-8-2. PP 579-583

\section{Copyrights}

Copyright for this article is retained by the author(s), with first publication rights granted to the journal. This is an open-access article distributed under the terms and conditions of the Creative Commons Attribution license (http://creativecommons.org/licenses/by/4.0/). 